\title{
Manejo da pastagem de milheto para recria novilhas de corte
}

\author{
Pearl Millet pasture management for rearing of beef heifers
}

\author{
Denise Baptaglin Montagner ${ }^{\mathrm{I}}$ Marta Gomes da Rocha ${ }^{\mathrm{II}}{ }^{*}$ Davi Teixeira dos Santos ${ }^{\mathrm{I}}$ \\ Teresa Cristina Moraes Genro ${ }^{\text {III }}$ Fernando Luiz Ferreira de Quadros ${ }^{\text {II }}$ Juliano Roman \\ Luciana Pötter ${ }^{\mathrm{I}}$ Carolina Bremm ${ }^{\mathrm{I}}$
}

\section{RESUMO}

Neste trabalho foram avaliados o desempenho de novilhas de corte e o retorno econômico da pastagem de milheto (Pennisetum americanum (L.) Leeke) manejada em duas massas de lâminas foliares (MLF). As MLF observadas foram de 642 e $1.024 \mathrm{~kg} \mathrm{ha}^{-1}$ de matéria seca (MS) e denominadas de '600' $e$ '1.000'. Os valores de ganho de peso diário, carga animal, ganho de peso por área e escore de condição corporal foram semelhantes $(P>0,05)$ nas massas de lâminas foliares avaliadas. A utilização de milheto, com massa de lâminas foliares com valores entre 600 e $1.000 \mathrm{~kg} \mathrm{ha}^{-1} \mathrm{MS}$, promove ganhos individuais satisfatórios em novilhas de corte, que permitem o seu adequado desenvolvimento para acasalamento aos 18-20 meses, e o retorno financeiro direto médio de $R \$ 2,9$ para cada real investido.

Palavras-chave: eficiência econômica, escore de condição corporal, massa de lâminas foliares, Pennisetum americanum.

\section{ABSTRACT}

A study was conducted to evaluate the influence of Pearl Millet pasture (Pennisetum americanum (L.) Leeke) leaf lamina mass (LLM) on beef heifers performance and financial return. The observed $L L M$ were 642 and $1.024 \mathrm{~kg} \mathrm{ha}^{-1}$ of dry matter (DM) and identified as '600' and '1000'. Daily weight gain, stocking rate, gain per area and body condition score averages were not affected $(P>0.05)$ by changes on LLM. Pearl millet pasture managed between 600 and $1000 \mathrm{~kg} \mathrm{ha}^{-1}$ of LLM promotes satisfactory beef heifers individuals gains, which allows their mating at 18/20 months of age and average direct financial return of 2.9 for each real invested.

Key words: economic efficiency, body condition score, leaf lamina mass, Pennisetum americanum.

\section{INTRODUÇÃO}

A redução na idade ao primeiro acasalamento de novilhas de corte é uma alternativa de manejo que pressupõe uma intensificação na utilização de recursos forrageiros. O milheto (Pennisetum americanum), gramínea de ciclo estival, pode ser incluído no planejamento alimentar destes animais, visando acelerar seu desenvolvimento, especialmente quando há previsão para seu acasalamento aos 18-20 meses de idade. Além da utilização de uma espécie forrageira que agrega qualidade ao sistema alimentar, estratégias de manejo da pastagem cultivada podem otimizar o desempenho individual e/ou a produção por unidade de área.

A manipulação do valor da massa de forragem constitui uma estratégia de manejo de pastagens e está relacionada com a oferta de forragem ao animal em pastejo. Em gramíneas tropicais, a massa de forragem pode não predizer corretamente as condições do pasto, pois o crescimento de colmos, com o avanço do ciclo produtivo, promove aumento significativo no acúmulo de biomassa na pastagem, modificando a capacidade de apreensão pelo animal em pastejo (SBRISSIA \& SILVA, 2001).

O manejo de forrageiras tropicais baseado na massa de lâminas foliares pode ser mais adequado no que se refere à quantificação da forragem prontamente disponível para o pastejo. Para o milheto,

IPrograma de Pós-graduação em Zootecnia, Universidade Federal de Santa Maria (UFSM), Santa Maria, RS, Brasil.

ID Departamento de Zootecnia, UFSM. *Endereço para correspondência: Rua Tuiuti, 1554/20, 97015-662, Santa Maria, RS, Brasil.

E-mail: mgdarocha@gmail.com.

IIEmbrapa - CPPSul, Bagé, RS, Brasil. 
não existem recomendações especificas a respeito do valor da massa de lâminas foliares que deve ser utilizado, para assegurar a máxima eficiência de pastejo. $\mathrm{O}$ valor da massa de forragem (MF) recomendada, 2000kg ha-1 de MS, proporcionou massa de lâminas foliares de $638 \mathrm{~kg} \mathrm{ha}^{-1}$ de MS (AITA, 1995). Já SCHWARTZ et al. (2003) observaram massa de lâminas foliares de 1009 e $624 \mathrm{~kg} \mathrm{ha}^{-1}$ de MS quando o milheto foi manejado com MF de 1770 e $1125 \mathrm{~kg} \mathrm{ha}^{-1}$ de MS, respectivamente.

O valor do ganho de peso diário, antes da estação de acasalamento, está relacionado com a possibilidade de as novilhas alcançarem ou não o pesoalvo pretendido nesta ocasião. Por outro lado, para altas taxas de prenhez, é necessário que o maior número possível de novilhas alcancem esta condição. Estes dois aspectos exprimem a importância da otimização do recurso forrageiro, por meio da busca do ponto ótimo para contemplar, concomitantemente, variáveis relacionadas com o desenvolvimento animal e a taxa de lotação da pastagem, para melhor utilização econômica dos pastos tropicais.

Este experimento teve por objetivo realizar uma apreciação bioeconômica da pastagem de milheto, manejada sob duas massas de lâminas foliares, utilizada por novilhas de corte para acasalamento aos 18-20 meses de idade.

\section{MATERIAL E MÉTODOS}

O experimento foi desenvolvido em área do Departamento de Zootecnia da Universidade Federal de Santa Maria (UFSM), localizada na Depressão Central do Estado do Rio Grande do Sul, com altitude de $95 \mathrm{~m}$, latitude $29^{\circ} 43^{\prime}$ Sul e longitude $53^{\circ} 42^{\prime}$ Oeste. $\mathrm{O}$ clima da região é Cfa (subtropical úmido), conforme classificação de Köppen (MORENO, 1961). Na figura 1 são apresentadas as temperaturas mínima, média e máxima $\left({ }^{\circ} \mathrm{C}\right)$, a precipitação pluviométrica média mensal (mm) e a radiação solar global mensal (min). Os dados foram obtidos na Estação Meteorológica do Departamento de Fitotecnia da UFSM.

O solo da área experimental é classificado como Argissolo Vermelho Distrófico Arênico, pertencente à unidade de mapeamento São Pedro (EMBRAPA, 1999). Os resultados da análise de solo apresentaram os seguintes valores: $\mathrm{pH}$ em $\mathrm{H}_{2} \mathrm{O}=4,1$; $\mathrm{Al}^{+++}=2,4 \mathrm{cmol} \mathrm{L}^{-1} ; \mathrm{Ca}^{++}=1,8 \mathrm{cmol} \mathrm{L}{ }^{-1} ; \mathrm{Mg}^{++}=0,5 \mathrm{cmol}$ $\mathrm{L}^{-1} ; \mathrm{CTC}=11,9 \mathrm{cmol} \mathrm{L}_{\mathrm{C}}^{-1} ; \mathrm{K}^{+}=101,7 \mathrm{mg} \mathrm{L}^{-1} ; \mathrm{P}=23,0 \mathrm{mg} \mathrm{L}^{-1}$ e $\mathrm{MO}=3,4 \%$.

A área experimental foi constituída de 6,0ha, divididos em seis subáreas de 0,7ha, mais uma área contígua de 1,8ha para animais reguladores da massa de lâminas foliares do pasto. A semeadura foi realizada pelo sistema de plantio direto, utilizando-se $35 \mathrm{~kg} \mathrm{ha}^{-1}$ de sementes de milheto e $280 \mathrm{~kg} \mathrm{ha}^{-1}$ de adubo NPK da fórmula 5-20-20. Foram aplicados $195 \mathrm{~kg}$ de nitrogênio (N) em cobertura, na forma de uréia, divididos em três aplicações.

Foram avaliadas duas massas de lâminas foliares (MLF): 500 e $1000 \mathrm{~kg} \mathrm{ha}^{-1}$ de matéria seca (MS). A estimativa da massa de lâminas foliares foi realizada a cada 15 dias, por ocasião da dupla amostragem (WILM, 1944), em 20 pontos aleatórios, com 20 estimativas visuais e cinco cortes, rente ao solo. As amostras coletadas foram separadas manualmente em lâmina foliar, colmo + bainha foliar e material morto, de modo a determinar a porcentagem de lâminas foliares presentes no dossel e a MLF. A taxa de acúmulo de forragem foi medida em três gaiolas de exclusão ao pastejo por repetição.

Foram utilizadas novilhas de corte da raça Charolês e também foram utilizados produtos do cruzamento Charolês-Nelore, com idade e peso médios iniciais de 15 meses e 230kg. O método de pastejo adotado foi contínuo com lotação variável (MOTT \& LUCAS, 1952). Os animais foram pesados nos dias 31/12, 26/01, 24/02, 24/03 e 04/04, com jejum prévio de sólidos e líquidos de $12 \mathrm{~h}$. Em todas as pesagens as novilhas foram submetidas a uma avaliação subjetiva da condição corporal (ECC, adaptado de LOWMAN et al., 1976), com escores de 1 (magro) a 5 (gordo), atribuídos por observação visual. Em cada período experimental, o ganho de peso diário médio (GDM) foi obtido pela diferença de peso entre as pesagens, dividido pelo número de dias do período. A carga animal média (CA) foi calculada pelo somatório do peso médio dos animais-teste, mais o produto do peso médio de cada animal regulador com o número de dias que este permaneceu na unidade experimental, dividido pelo número de dias do período. A lotação média (LOT) foi obtida pelo quociente da carga animal com o peso médio das novilhas, $250 \mathrm{~kg}$. O ganho de peso vivo por área foi obtido pelo somatório do ganho de peso dos animais-teste, mais o produto do GDM dos animais reguladores com o número de dias em que estes permaneceram no piquete.

Com os resultados de MF, carga animal e taxa de acúmulo de MS, foi calculada a oferta de forragem, em $\mathrm{kg}$ de $\mathrm{MS} 100 \mathrm{~kg}$ de $\mathrm{PV}^{-1}$. Com os resultados de produção de lâmina foliar e carga animal, foi calculada a oferta de lâminas de folhas verdes, em kg de MS de lâminas de folhas verdes por $100 \mathrm{~kg}$ de PV.

Amostras da forragem aparentemente consumida pelos animais em pastejo, coletadas por dois avaliadores treinados, em cada unidade experimental, por meio da técnica de simulação do 


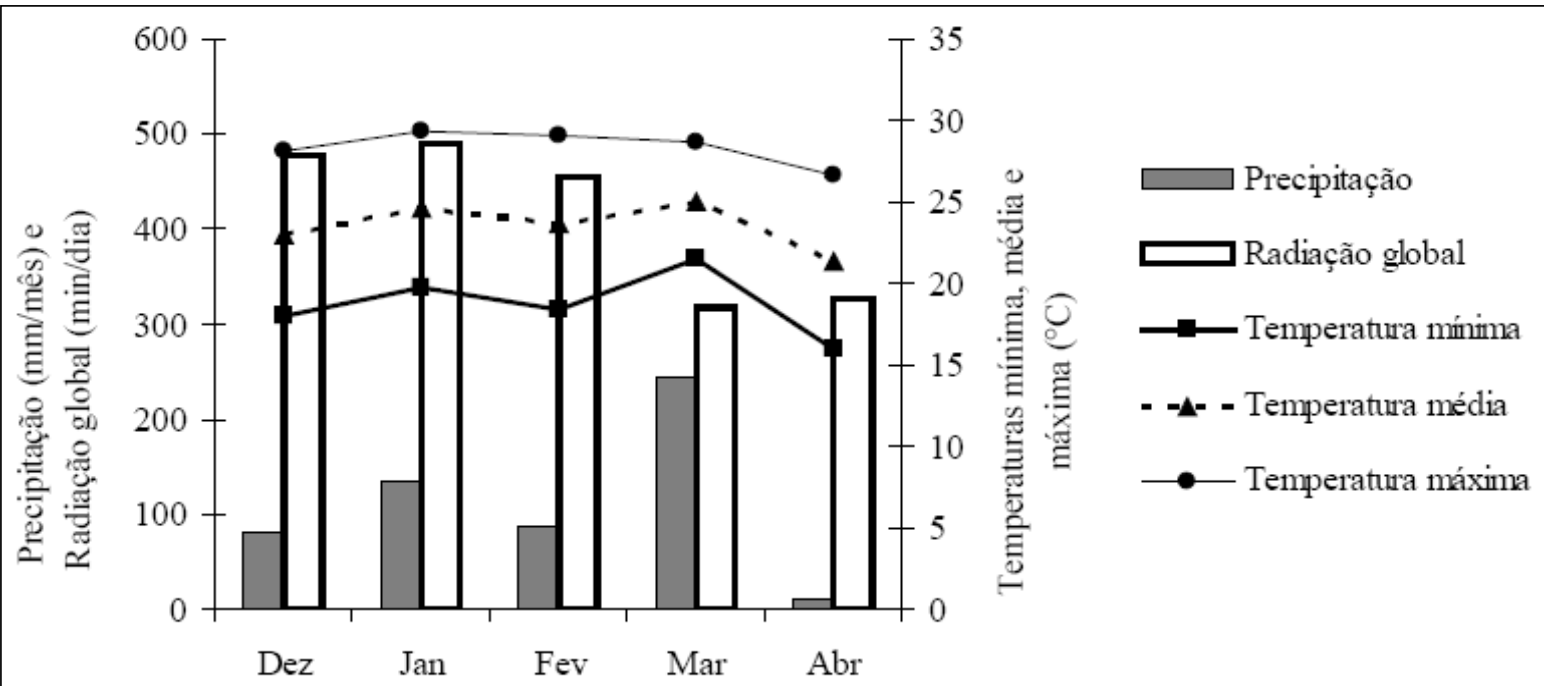

Período experimental

Figura 1 - Precipitação pluviométrica $(\mathrm{mm})$, radiação global (min), temperaturas média, máxima e mínima ( $\left.{ }^{\circ} \mathrm{C}\right)$ do período de dezembro de 2001 a abril de 2002 no campus da Universidade Federal de Santa Maria.

pastejo (EUCLIDES et al., 1992), foram utilizadas para a determinação do conteúdo de proteína bruta (PB, \%; AOAC, 1995), da digestibilidade in vitro da matéria orgânica (DIVMO, \%; TILLEY \& TERRY, 1963) e do teor de fibra em detergente neutro (FDN, \%; AOAC, 1995).

A avaliação econômica foi realizada com a utilização de planilhas de cálculo do Microsoft Excel ${ }^{\circledR}$, versão 2000, segundo modelo proposto por PÖTTER et al. (1998). Os preços utilizados para o cálculo dos custos totais, bem como para a conversão dos valores para kg de PV de novilha, foram obtidos a partir de uma pesquisa de mercado efetuada em junho de 2007, na região de Santa Maria, RS. O custo da mão-de-obra foi estabelecido a partir do salário mínimo rural do Estado, somado aos encargos sociais. Considerou-se um total de 220 horas mensais de trabalho (PÖTTER et al., 1998). Para os custos de hora-trator, foram somados os gastos de depreciação, conservação, combustíveis, lubrificantes e mão-de-obra e, para os implementos, foram computados os custos de depreciação e conservação. Da relação receita bruta (RB)/custo total (CT), obteve-se o retorno financeiro direto (RFD) por tratamento. A margem bruta (MB) de cada operação foi obtida pela diferença entre RB e CT.

O delineamento experimental foi inteiramente casualizado, com medidas repetidas no tempo, com dois tratamentos e três repetições de área. Os dados foram submetidos à análise de variância e Teste F em 5\% de significância, utilizando-se o procedimento MIXED e, quando detectadas diferenças entre as médias, estas foram comparadas pelo teste t de Student (PDIFF), utilizando-se o pacote estatístico SAS (1996).

\section{RESULTADOS E DISCUSSÃO}

O período de utilização da pastagem de milheto foi de 94 dias, de 31 de dezembro de 2001 a 04 de abril de 2002. Na tabela 1, são apresentados os valores de massa e oferta de lâminas foliares observados, de acordo com os dias de utilização da pastagem. Para facilitar a discussão e a recomendação de manejo, as massas observadas passam a ser denominadas de '600' e ‘1.000’, valores próximos aos encontrados. A massa de lâminas foliares ficou próxima da preconizada nos períodos iniciais de utilização da pastagem. A precisão das estimativas visuais foi reduzida no final do ciclo de pastejo devido ao alongamento de colmos do milheto e ao aumento no acúmulo de material morto, e dificultou a manutenção do valor pretendido da massa de lâminas foliares. A massa de forragem média foi de 1.453,9 e $2.498,6 \mathrm{~kg} \mathrm{ha}^{-1} \mathrm{MS}$, respectivamente para 600 e $1.000 \mathrm{~kg}$ ha $^{-1}$ de MS de lâminas foliares.

Não houve interação entre massa de lâminas foliares e período de avaliação $(\mathrm{P}=0,9486)$ e não houve diferença $(\mathrm{P}=0,6836)$ para oferta de lâminas foliares nas massas de lâminas foliares avaliadas.

Com o avanço do ciclo vegetativo e o início do período reprodutivo, foram observadas menores ofertas de lâminas foliares ( $\mathrm{P}=0,0377)$, pois, em pastos tropicais, o alongamento de colmos aumenta em detrimento ao alongamento de lâminas foliares (SILVA, 
Tabela 1 - Massa de lâminas foliares (kg ha ${ }^{-1} \mathrm{MS}$ ) observada e oferta de lâminas foliares (kg MS 100 kg PV ${ }^{-1}$ ) em pastagem de milheto, de acordo com o período de avaliação.

\begin{tabular}{|c|c|c|c|c|}
\hline \multirow{2}{*}{$\operatorname{MLF}\left(\mathrm{kg} \mathrm{ha}^{-1} \mathrm{MS}\right)$} & \multicolumn{3}{|c|}{ Dias após o início da utilização da pastagem } & \multirow{2}{*}{ Média } \\
\hline & $1-26$ & $27-54$ & $55-94$ & \\
\hline \multicolumn{5}{|c|}{ Massa de lâminas foliares (kg ha ${ }^{-1}$ de MS) } \\
\hline 600 & 449,30 & 490,10 & 985,70 & $641,70 b$ \\
\hline 1.000 & 773,60 & 904,20 & 1393,70 & $1023,80 a$ \\
\hline \multicolumn{5}{|c|}{ Oferta de lâminas foliares (kg MS $100 \mathrm{~kg} \mathrm{PV}^{-1}$ ) } \\
\hline 600 & 8,78 & 10,40 & 4,43 & 7,87 \\
\hline 1.000 & 9,55 & 10,39 & 6,97 & 9,00 \\
\hline Média & $9,17 \mathrm{AB}$ & $10,40 \mathrm{~A}$ & $5,70 \mathrm{~B}$ & \\
\hline
\end{tabular}

Letras maiúsculas na mesma linha diferem estatisticamente para média dos dias de avaliação ( $<00,05)$.

Letras minúsculas na mesma coluna diferem estatisticamente para massas de lâminas foliares $(\mathrm{P}<0,05)$.

2004). Conforme HODGSON (1990), para que não ocorra limitação no consumo voluntário de animais em pastejo, a oferta de forragem deve ser cerca de quatro vezes o valor do consumo potencial dos animais. Para novilhas, com idade média de 18 meses, o consumo estimado de MS é de 2,5\% do PV (NATIONAL RESEARCH COUNCIL - NRC, 1996) e o valor médio de $8,42 \mathrm{~kg}$ de PV de oferta de lâminas foliares, provavelmente, foi suficiente para que os animais em pastejo pudessem selecionar preferencialmente lâminas foliares na forragem disponível.

Na figura 2 são apresentados os valores médios para ganho de peso diário médio (GMD, kg), peso vivo (kg), escore de condição corporal (ECC, 15), carga animal ( $\mathrm{kg} \mathrm{ha}^{-1} \mathrm{PV}$ ), taxa de lotação e ganho de peso vivo por área $\left(\mathrm{kg} \mathrm{ha}^{-1} \mathrm{de} \mathrm{PV}\right)$. O ganho de peso vivo diário médio e o $\mathrm{ECC}$ não diferiram $(\mathrm{P}>0,05)$ para animais em pastagem com ' 600 ' ou ' 1.000 ' $\mathrm{kg} \mathrm{ha}^{-1} \mathrm{de}$ massa de lâminas foliares. Para desempenho semelhante, deve ter existido a oportunidade idêntica de consumo de MS e seleção de lâminas foliares nas duas MLF avaliadas. O GMD, em espécies C4, como o milheto, conforme SOLLENBERGER \& BURNS (2001), depende não só da quantidade de lâminas foliares, mas também da forma com que as folhas são apresentadas aos animais e o grau com que estas podem ser apreendidas em separado do pseudocolmo e do material morto, de baixa digestibilidade. Assim, a acessibilidade das folhas aos animais em pastejo, mais do que o seu valor numérico, deve ter determinado o desempenho individual dos animais.

Menores ganhos individuais $(\mathrm{P}=0,0118)$ foram observados no inicio da utilização da pastagem de milheto, em relação aos períodos posteriores e, provavelmente, resultaram da adaptação dos animais a nova área e manejo.
O ganho de peso médio diário observado foi de $0,777 \mathrm{~kg}$ (Figura 2). Na forragem consumida, o teor de proteína bruta, $16,2 \% \mathrm{~PB}$, poderia ter promovido ganhos de até 1,5kg/animal/dia (NRC, 1996). Os teores de fibra (63,7\% FDN) e digestibilidade do pasto (57,9\% DIVMO), no entanto, proporcionaram ganhos individuais mais modestos, pois conforme VAN SOEST (1994), o consumo dos animais em pastejo é limitado por meio de efeitos físicos, como o enchimento ruminal e o tempo de passagem da dieta pelo trato gastrintestinal.

Ganhos individuais próximos a $0,800 \mathrm{~kg} \mathrm{dia}^{-1}$, em pastagem de milheto, podem ser considerados suficientes para que novilhas cruzadas CharolêsNelore possam ser acasaladas aos 18 meses de idade (ROCHA et al., 2004) . A pastagem de milheto, mesmo que utilizada em período aproximado de 90 dias, promove ganhos individuas superiores aos potencialmente obtidos em campo nativo, $0,500 \mathrm{~kg} \mathrm{dia}^{-1}$, tornando possível a intensificação do sistema de produção pecuário. Também neste período, decorrente da carga animal e do GMD, foi possível produzir uma tonelada de PV por hectare (Figura 2B).

Valores mais elevados do escore de condição corporal $(\mathrm{P}=0,0059)$ foram observados ao final do ciclo de utilização da pastagem, quando os animais alcançaram peso vivo médio de $305 \mathrm{~kg}$. Ao final do período de utilização da pastagem de milheto, as novilhas apresentavam $67 \%$ do peso de fêmeas bovinas adultas (450kg). Este peso e também o escore de condição corporal de 3,2, ao final da utilização da pastagem podem ser considerados adequados para que as novilhas apresentem estros regulares na estação de monta subseqüente (SANTOS et al., 2005).

Não foram observadas diferenças entre massas de lâminas foliares e entre períodos de utilização 


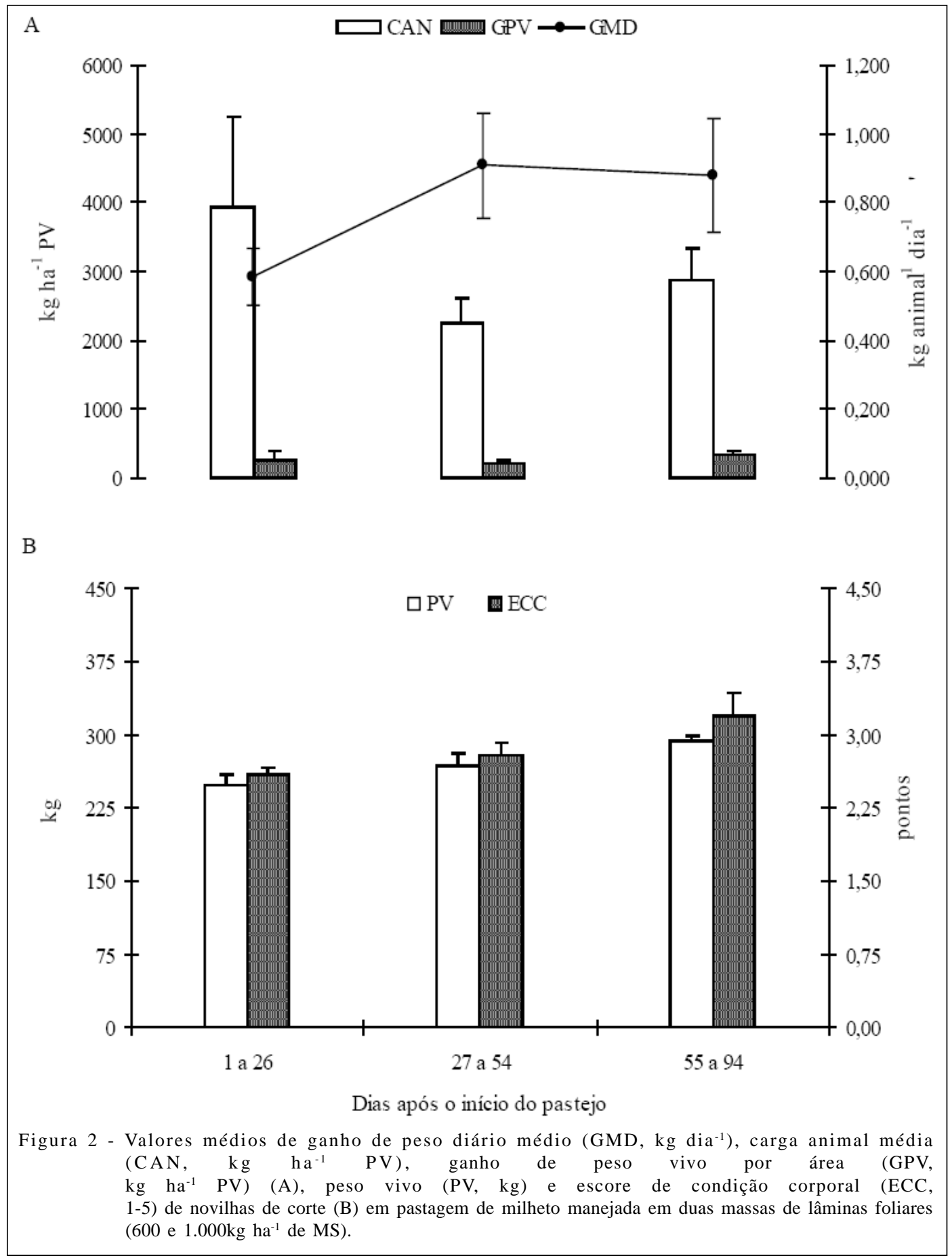

da pastagem de milheto para carga animal e ganho de peso vivo $(\mathrm{P}>0,05)$. A taxa de lotação foi diferente entre os dias de utilização da pastagem de milheto $(\mathrm{P}=0,0423)$. A carga animal média, em valores numéricos, foi $578,1 \mathrm{~kg}$ a mais quando o pasto foi manejado com MLF de ‘600' $\mathrm{kg} \mathrm{ha}^{-1}$ de MS (3.119,9 e 2.541,8kg ha-1 PV, respectivamente para '600' e ‘ 1000 ' $\mathrm{kg} \mathrm{ha}^{-1}$ MS de lâminas foliares). Foram verificadas taxas de lotação de 11,8 e 10,0 novilhas por hectare, respectivamente para as massas de lâminas foliares de '600' e '1000' $\mathrm{kg} \mathrm{ha}^{-1}$ de MS, o que equivale a 6,5 e 5,6 unidades animal (UA) por hectare (UA=450kg PV).

Na tabela 2, é apresentado o resumo da análise econômica da utilização da pastagem de milheto. A soma dos gastos com semeadura, adubação de base 
Tabela 2 - Resumo da análise econômica da utilização de pastagem de milheto manejada em duas massas de lâminas foliares (MLF). Valores atualizados em junho de 2007.

\begin{tabular}{|c|c|c|c|c|}
\hline \multirow{3}{*}{ Parâmetros econômicos } & \multicolumn{4}{|c|}{--------------------------------------MLF (kg ha'1 MS) -------------------------------------- } \\
\hline & \multicolumn{2}{|c|}{---------------------600-------------------- } & \multicolumn{2}{|c|}{------------------1.000------------------- } \\
\hline & $\mathrm{R} \$ \mathrm{ha}^{-1}$ & $\mathrm{~kg} \mathrm{ha}^{-1} \mathrm{PV}^{* *}$ & $\mathrm{R} \$ \mathrm{ha}^{-1}$ & $\mathrm{~kg} \mathrm{ha}^{-1} \mathrm{PV}$ \\
\hline Custo da pastagem & 637,5 & 321,9 & 637,5 & 321,9 \\
\hline - dessecante + operação & 21,9 & 11,1 & 21,9 & 11,1 \\
\hline - semeadura + adubação & 129,2 & 65,3 & 129,2 & 65,3 \\
\hline - adubo & 210,0 & 106,0 & 210,0 & 106,0 \\
\hline - uréia & 249,4 & 125,9 & 249,4 & 125,9 \\
\hline - arrendamento & 27,0 & 13,6 & 27,0 & 13,6 \\
\hline Custo adicional* & 62,7 & 31,6 & 51,2 & 25,8 \\
\hline Custo total & 700,2 & 353,6 & 688,7 & 347,8 \\
\hline Receita bruta & $2.316,0$ & $1.169,7$ & $1.827,5$ & 923,0 \\
\hline Margem bruta & $1.615,8$ & 816,0 & $1.138,8$ & 575,2 \\
\hline Retorno financeiro direto & \multicolumn{2}{|c|}{3,3} & \multicolumn{2}{|c|}{2,6} \\
\hline
\end{tabular}

*custos referentes à utilização de sal e vermífugo.

**kg PV novilha $=$ R\$ 1,98.

e adubação nitrogenada constituem 90,70\% do custo total de implantação da pastagem, totalizando um custo de R\$ 578,06 ao sistema.

A amplitude numérica verificada nos valores de carga animal entre as duas massas de lâminas foliares, para custo idêntico, promoveu retorno econômico de R \$ 3,3 e R \$ 2,6 para cada R \$ 1,0 investido em milheto manejado com MLF de ‘600' ou ‘ 1000 ’ $\mathrm{kg}$ $\mathrm{ha}^{-1}$ de MS. O valor médio de retorno financeiro direto foi de 2,9kg No ano agrícola de 2006/2007, mesmo com os elevados preços praticados pelo mercado de insumos, a utilização de pastagem de milheto para a produção de bovinos de corte mostrou-se bastante eficiente biológica e economicamente, constituindose em importante alternativa para a recria de novilhas de corte a pasto.

\section{CONCLUSÕES}

Ganhos individuais satisfatórios em novilhas de corte são obtidos quando a pastagem de milheto é manejada com massa de lâminas foliares entre 600 e $1.000 \mathrm{~kg} \mathrm{ha}^{-1} \mathrm{MS}$, com resultados econômicos positivos.

\section{REFERÊNCIAS}

AITA, V. Utilização de diferentes pastagens de estação quente na recria de bovinos de corte. 1995. 103f. Dissertação (Mestrado em Zootecnia) - Universidade Federal de Santa Maria.
ASSOCIATION OF OFFICIAL ANALYTICAL CHEMISTSAOAC. Official methods of analysis. 14.ed. Washington, 1995. 1141p.

EMBRAPA- Centro Nacional de Pesquisa de Solos. Sistema brasileiro de classificação de solos. Brasília / Rio de Janeiro, 1999. 412p.

EUCLIDES, V.P.B. et al. Avaliação de diferentes métodos de amostragem sob pastejo. Revista Brasileira de Zootecnia, v.21, n.4, p.691-702, 1992.

HODGSON, J. Grazing management: science into practice. New York: John Wiley \& Sons, 1990. 203p.

LOWMAN, B.G. et al. Condition scoring beef cattle. Edinburgh: East of Scotland College of Agriculture, 1976. 8p. (Bulletin 6).

MORENO, J.A. Clima do Rio Grande do Sul. Porto Alegre: Secretaria da Agricultura, 1961. 41p.

MOTT, G.O.; LUCAS, H.L. The design conduct and interpretation of grazing trials on cultivated and improved pastures. In: INTERNATIONAL GRASSLAND CONGRESS, 6., 1952, Pensykvania. Proceedings... Pensylvania: State College, 1952. p.1380-1395.

NRC - NATIONAL RESEARCH COUNCIL. Nutrient requirement of beef cattle. 7.ed. Washington: National Academy, 1996. 90p.

PÖTTER, L. et al. Produtividade de um modelo de produção de para novilhas de corte primíparas aos dois, três e quatro anos de idade. Revista Brasileira de Zootecnia, v.27, n.3, p.613619, 1998.

ROCHA, M.G. et al. Desenvolvimento de novilhas de corte submetidas a diferentes sistemas alimentares. Revista 
Brasileira de Zootecnia, v.33, n.6, supl.2, p.2123-2131, 2004.

SAS- INSTITUTE SAS/STAT. User's guide: statistics. 4.ed. Version 6.08. Cary, NC, 1996. V.2, 1014p.

SANTOS, D.T. et al. Suplementos energéticos para recria de novilhas de corte em pastagens anuais. Desempenho animal. Revista Brasileira de Zootecnia, v.34, n.1, p.209-219, 2005.

SBRISSIA, A.F.; SILVA, S.C. O ecossistema de pastagens e a produção animal. In: REUNIÃO ANUAL DA SOCIDADE BRASILEIRA DE ZOOTECNIA, 38., 2001, Piracicaba. Anais... Piracicaba: SBZ, 2001. p.731-754.

SCHWARTZ, F. et al. Manejo de milheto (Pennisetum americanum Leeke) sob pastejo de ovinos. Revista Brasileira de Agrociência, v.9, n.2, p.151-155, 2003.

SILVA, S.C. Fundamentos para o manejo do pastejo de plantas forrageiras dos gêneros Brachiaria e Panicum. In: SIMPÓSIO
SOBRE MANEJO ESTRATÉGICO DA PASTAGEM, 2., 2004, Viçosa. Anais... Viçosa: UFV, DZO, 2004. p.347-386.

SOLLENBERGER, L.E., BURNS, J.C. Canopy characteristics, ingestive behavior and herbage intake in cultivated tropical grasslands. In: INTERNATIONAL GRASSLAND CONGRESS, 19., 2001, Piracicaba. Proceedings... Piracicaba: FEALQ, 2001. p.321-327.

TILLEY, J.M.A.; TERRY, R.A. A two-stage technique for the "in vitro" digestion of forage crop. Journal British Grassland Society, v.18, n.2, p.104-111, 1963.

VAN SOEST, P.J. Nutritional ecology of the ruminant. 2.ed. Ithaca: Cornell University, 1994. 476p.

WILM, H.G. et al. Estimating forage yield by the doublesampling methods. Journal American Society Agronomy, n.36, p.194-203. 1944. 